\title{
La muerte del poeta. Funeral de estado y ritual social en el falleci- miento de José Zorrilla (1893)
}

\section{Raquel Sánchez García}

Universidad Complutense

RESUMEN: Durante el siglo XIX, el Estado intentó crear unos rituales civiles capaces de sustituir o complementar a las ceremonias militares y religiosas. Los funerales de estado formaron parte de estos rituales. En ellos se mezclaron distintos componentes que trataban de proyectar sobre la sociedad los valores de la nación y del liberalismo. Este artículo analiza dicho proceso siguiendo como eje los funerales del poeta José Zorrilla (enero de 1893). En los funerales de Zorrilla se observa el intento del Estado por protagonizar la ceremonia, la presencia de la Iglesia en todo el proceso y la voluntad del finado, que no fue respetada en absoluto. Para llevar a cabo el trabajo, se utiliza la información procedente de diversas fuentes y se aplica una metodología de análisis basada en el estudio de los rituales cívicos como ceremonias sociales.

\section{PALABRAS CLAVE: Escritores; cultura; nacionalismo español; funera- les de estado; rituales políticos; liberalismo.}

The Death of the Poet. State Funeral and Social Ritual in the Death of José Zorrilla (1893)

ABSTRACT: During the nineteenth century, the State attempted to create civil rituals to replace or supplement military and religious ceremonies. State funerals were part of these rituals that mixed different components trying to project onto society the values of the nation and the liberalism thought. This article analyzes this process through the funeral of the poet José Zorrilla (January 1893). In Zorrilla's funeral it can be seen the attempt of the State for starring in the ceremony, the presence of the Church in the whole process and the will of the deceased that was not respected at all. To carry out the work, it has been used information from various sources 
and it has been applied a methodology of analysis based on the study of civic rituals as social ceremonies.

KEY WORDS: Writers; culture; Spanish nationalism; state funerals; political rituals; liberalism.

Un fenómeno propio de las sociedades modernas es el de la presencia pública del mundo de la cultura con un sentido mucho más político que en épocas anteriores. Es muy cierto que la cultura ha sido a lo largo de la historia instrumento a favor o en contra el poder político, pero en la sociedad del siglo XIX, y sobre todo a finales de la centuria, la presencia pública del creador es muy evidente. Estamos en el momento de la aparición de la figura del intelectual como agente crítico y como agente político, como creador de representaciones del imaginario acerca de la comunidad. El poeta-profeta del que habló Paul Bénichou, figura que se conformó entre el final del siglo XVIII y la primera mitad del XIX, alcanzó a finales de siglo una mayor complejidad ${ }^{1}$. La instrumentalización político-nacionalista de la cultura a través de las instituciones públicas en las sociedades burguesas ha sido ingrediente básico en la formación del Estado contemporáneo, especialmente por lo que la cultura puede aportar en el terreno de la cohesión interna, por sus relecturas del pasado. La consideración de determinados creadores como poetas nacionales es un ejemplo claro del reconocimiento del artista literario como portavoz de unos valores aceptados por todos. Los homenajes públicos y las llamadas «coronaciones» de estos poetas nacionales se articularon en forma de ceremonias que validaban socialmente al autor y lo unían al país cuyo espíritu su obra expresaba.

Otra de las ceremonias que evidencia la presencia del autor como personaje público es la de sus funerales. Todas las sociedades celebran honras fúnebres entendidas como ritos de paso por los que han de transitar los individuos que forman parte de ellas. Sin embargo, estos ritos no son semejantes para todos los miembros de la comunidad. Sólo cuando fallecen los poderosos o aquellos que han tenido la capacidad de representar la conexión con lo sagrado o con los valores colectivos es cuando se considera necesario que ha de hacerse partícipe de las ceremonias a toda la comunidad ${ }^{2}$. En las modernas sociedades, estos ritos se han sofisticado pero no han dejado de celebrarse y de tener un significado simbólico de primera importancia. Ahí alcanzan su sentido los funerales de estado. No todos los poetas y escritores significativos conocieron este tipo de funerales en la España del siglo XIX. A lo largo del trabajo se irán viendo varios ejemplos de ello, pero en este momento se puede

1 BÉNICHOU, 1981. Para España: ÁLVAREZ BARRIENTOS (ed.), 2004 y 2006.

2 Una evolución histórica en RADER, 2006. 
avanzar la idea de que un autor era objeto de homenaje no tanto por razones estéticas como por razones políticas. Es decir, que del escritor se tenía en especial consideración su participación en la defensa de los valores de quienes en el momento de su muerte estaban en el gobierno (caso de Francisco Martínez de la Rosa) o por el hecho de que su obra fuera la expresión de la cosmovisión nacional predominante (caso de José Zorrilla).

La conexión entre los creadores culturales «politizados» (incluso a su pesar) y la utilidad pública de sus trayectorias vitales y/o mensajes literarios resulta evidente si se tiene en cuenta que los poetas que fueron coronados como poetas nacionales en ceremonias de gran relevancia fueron los mismos a los que se les tributaron funerales de estado más sofisticados. Estos dos poetas fueron Manuel José Quintana y José Zorrilla ${ }^{3}$.

El funeral de estado se desarrolló en España de forma paralela a la implantación del régimen liberal, como un elemento más del conjunto de ceremonias que creó el nuevo régimen como forma de autolegitimación a través de elementos simbólicos y rituales que expresasen los valores de la nación liberal. El nuevo ritual convivió con el ritual funerario de la monarquía, que a su vez conoció en el siglo XIX un proceso de descomposición de su rigidez cortesana y que en ciertos momentos sirvió si no de imitación, sí de estímulo para la creación de los rituales funerarios del $E \operatorname{stado}^{4}$. Se ha señalado que surgió ya en la época de las Cortes de Cádiz un deseo de adecuar el viejo ceremonial de la monarquía absoluta a los requerimientos simbólicos de la monarquía constitucional. La estricta separación que existía en el homenaje final al monarca entre la corte y el gobierno comenzó a hacerse incómoda en el siglo XIX, especialmente por el papel secundario que tenían las autoridades gubernativas en los actos. Cuando se produjo la muerte del rey Alfonso XII (1885) en la prensa se llegó a leer lo siguiente: «no será mucho pedir que, a la vieja etiqueta de los reyes absolutos, sustituya la etiqueta de los reyes constitucionales» ${ }^{5}$, haciendo referencia a que el protocolo cortesano establecía que el traslado al monasterio de El Escorial y el entierro del rey constituían unos actos a los que sólo podían acudir la corte, los nobles y los religiosos ${ }^{6}$.

Este fenómeno no fue sólo propio de España. Avner Ben-Amos ha estudiado el proceso en Francia, donde fue especialmente significativo durante la

3 Sobre las coronaciones de ambos: PALENQUE, 2008; SÁNCHEZ GARCÍA, 2011b. A lo largo del siglo tuvieron lugar otras ceremonias de coronación, pero sin la trascendencia de las ya citadas.

4 VARELA, 1990.

5 La Época (30-11-1885), en VARELA, 1990: 174.

6 J. Varela señala que sólo en el traslado y entierro del infante Francisco de Paula Antonio en 1865 (el primer difunto de la familia real al que se trasladó al Escorial en tren) pudieron estar presentes delegados del gobierno, las Cortes y los tribunales, presididos por el jefe del gobierno, el general O’Donnell. 
Tercera República, momento en que el ceremonial tuvo que redefinirse a partir de los modelos monárquico y religioso, en el intento de establecer un ritual cívico, y en algunos casos, laico ${ }^{7}$. Sin embargo, en el caso español no existió ningún conflicto con el ritual católico porque ningún gobierno tuvo una vocación laicista tan fuerte como en la Francia republicana. En España se configuró una ceremonia que incluía elementos religiosos y políticos sin grandes conflictos. Lo que resulta común a casi todos los países europeos fue la intención de extender la tributación de honores de estado no sólo, como se ha dicho antes, a políticos, militares y reyes, sino a otros colectivos que expresaran los ideales políticos de la nación (en el caso español), de la república (en el caso francés), del imperio (en el caso inglés), etc. Para los escritores el camino resultó relativamente sencillo, ya que entre los siglos XVIII y XIX las producciones literarias y sus creadores se «nacionalizaron $»^{8}$. Evidentemente, podemos encontrar casos de escritores que fueron considerados universales en su momento, o defensores de valores universales, como Victor Hugo. Sin embargo, sus funerales fueron la expresión de unos valores universales de los que la Tercera República francesa se presentaba como portadora ${ }^{9}$. Se creó, de este modo, la figura del «gran hombre», representación metafórica de la nación que se encarna en un personaje cuya superioridad ética y cuya labor a favor del colectivo ha sido tan destacada que puede servir de ejemplo moral a todos los ciudadanos ${ }^{10}$.

Podría decirse que las ceremonias en honor a los grandes hombres del parnaso literario español comenzaron con el propio régimen liberal, aunque de forma modesta. Para ello era necesario, obviamente, que hubiese cambiado la percepción social acerca del escritor. Ello sólo era posible en una sociedad que comenzaba a ser abierta, y la española de los años treinta lo era, dentro de sus limitaciones. El escritor en el sentido que se comentó anteriormente, como agente crítico o como portavoz de ideales, se personificó en la España de esa época en Mariano José de Larra ${ }^{11}$. Sin embargo, su muerte por suicidio invalidó cualquier proyección social de Larra como ejemplo moral y dio más pie a censuras o a compasión que a otro tipo de sentimientos ${ }^{12}$. Por otra parte, su ácida reprobación de los comportamientos sociales asentados en la ascen-

7 BEN-AMOS, 2000.

8 MAINER, 2006: 201-230. Este proceso comenzó ya en el siglo XVIII (ÁLVAREZ BARRIENTOS, 2006: 280-284).

9 BEN-AMOS, 1997, vol. 1: 425-464.

10 El «gran hombre» en la sociedad liberal, precisamente por su ejemplaridad y moralidad, viene a ser la modernización y la secularización del santo, referente moral y de conducta de épocas anteriores. El culto a los grandes hombres fue decretado en 1791 por la Asamblea Nacional francesa.

11 ÁLVAREZ BARRIENTOS, 2011: 17-40.

12 El Eco del Comercio (18 y 19-2-1837). 
dente burguesía le hacían poco propicio para convertirse en un referente nacional compartido por todos. Algo distinto fue el caso de José Espronceda, cuya muerte por enfermedad el 23 de mayo de 1842 encajaba en los moldes vitales del artista romántico que muere joven. La prensa habló de él en esta línea al decir que se igualaba «con la muerte prematura de otros poetas con quienes tenía grandes rasgos de semejanza» ${ }^{13}$. Espronceda también fue crítico con la sociedad, pero en términos generales y poéticos. Su adscripción política en el bando más izquierdista del progresismo le permitía, además, convertirse en adalid de los valores humanitarios de libertad y revolución que tanto predicamento tuvieron en la época.

El camino emprendido en los primeros años del liberalismo se culmina con los funerales de Manuel José Quintana, figura aún más propicia a la confluencia de posicionamientos políticos que Espronceda. De hecho, el homenaje a este último no tuvo carácter oficial, cosa que sí le sucedió al segundo. Quintana murió en 1857, cuando el régimen liberal había alcanzado todos sus límites en materia de apertura política. Sin embargo, la gloria de Quintana remitía a un momento del pasado reciente que había quedado consensuado como el momento fundacional del liberalismo español: la Guerra de la Independencia. Quintana sí podía ser una gloria nacional salvo, desde luego, para los tradicionalistas que, en cualquier caso, se encontraban en los márgenes de la vida política.

El entierro de Quintana fue presidido por el ministro de Fomento (Claudio Moyano), la familia, los testamentarios y la comisión que organizó su coronación en 1855. Contó también con una delegación enviada por la reina. Las cintas del féretro fueron llevadas por representantes de las academias y de la administración pública, en una muy significativa unidad de las letras y el Estado. Como es fácil colegir, a Quintana se le tributó este homenaje (como el de su coronación) por su ejemplo político, no por su valor literario, cuestión que en él, como en tantos otros escritores, acabó por convertirse en algo accesorio. Sin embargo, resulta significativo que en 1857 el gobierno del moderado Narváez accediese a homenajear a un símbolo del liberalismo progresista, como había sido Quintana. Por otra parte, en el entierro de Quintana aparece ya un elemento recogido por la prensa y que será fundamental en los funerales de estado posteriores: la presencia de la multitud ${ }^{14}$.

\section{LA MUERTE DEL POETA}

La vida de Zorrilla recorre todo el siglo y su trayectoria es, en buena medida, la de la vida cultural española del siglo XIX. José Zorrilla representa el

13 El Genio de la Libertad (1-6-1842).

14 SÁNCHEZ GARCÍA 17 (Madrid, 2011a): 1-13. 
prototipo de poeta nacional situado más allá de las coyunturas políticas y de los partidos. Esta fue la razón por la que se le coronó en Granada como poeta nacional. A lo largo de la segunda mitad de la centuria, hubo otros escritores y poetas que también recibieron honores de estado, como Martínez de la Rosa o López de Ayala; y algunos de los que traspasaron la frontera el siglo, como Campoamor y Núñez de Arce, también recibieron funerales oficiales. Sin embargo, todos ellos desempeñaron cargos políticos de mayor o menor importancia y en las crónicas de sus funerales se insistió en su proyección política mucho más que en la literaria. En el caso de Zorrilla, la justificación de su homenaje estuvo en la lectura en clave nacionalista de su obra, que proponía una interpretación de la nación en términos retrospectivos, muy confortables para una España en crisis, como era la de fines del siglo ${ }^{15}$.

Todo ello facilitaba enormemente que su funeral pudiese ser manipulado por las autoridades y convertido en un gran acontecimiento, contra la voluntad del propio poeta y la de su familia. El proceso de organización y desarrollo del funeral de Zorrilla responde muy bien al concepto de ceremonia pública que Ben-Amos, siguiendo una perspectiva antropológica, denomina «el funeral de estado como drama social» ${ }^{16}$. Tuvo también una clara connotación de «fiesta» luctuosa con dos consecuencias básicas: por un lado, rompió el ritmo de la cotidianeidad por su proyección pública; por otro, sirvió como elemento de transmisión de valores en un momento emocional especialmente significativo ${ }^{17}$. El funeral de Zorrilla puede insertarse en el conjunto de conmemoraciones que tuvieron lugar en España entre las décadas finales del siglo XIX y las primeras del XX, celebraciones marcadas por un doble carácter de fiestas nacionalistas y de fiestas «de masas».

Zorrilla murió el 23 de enero de 1893 a los 75 años, después de padecer una enfermedad cerebral durante bastante tiempo. Había dejado escrito en su testamento que quería un entierro sencillo:

El testador suplica al Excmo. Ayuntamiento de esta ciudad [Valladolid], y le autoriza para ello, que apenas ocurra su defunción, reclame su cadáver si muere fuera de su ciudad natal, y le dé sepultura en su Cementerio ${ }^{18}$.

Lo mismo escribió a un amigo suyo en una carta que reprodujo la prensa:

15 SÁNCHEZ GARCÍA, 17 (Madrid, 2007): 205-222.

16 BEN-AMOS, 2000: 252-255.

17 GÉRÔME, 1994: 15-16.

18 Testamento otorgado en Valladolid el 19 de enero de 1884, Archivo Histórico Provincial de Valladolid, protocolo $\mathrm{n}^{\circ}$ 18756, folios 91-96. Reproducido también en ALONSO CORTÉS, 1943: 969-973. 
Tengo un grande afán por concluir mi vida en la oscuridad donde la luz de mi miserable gloria no llegue, y donde no arrastren mi cadáver por las calles dando el último escándalo de un entierro pagano, en que las cómicas me echen las últimas flores como a Voltaire o un histrión griego ${ }^{19}$

Sin embargo, su voluntad no se cumplió y su cuerpo fue sustraído a la intención de su familia de cumplir sus deseos. En casos como éste, la apropiación del cuerpo del difunto por parte del Estado convierte a aquél en un bien público desde el momento en que el difunto pasa a ser considerado gloria nacional y, por tanto, susceptible de homenaje. El caso de Zorrilla no fue único. A la muerte del poeta Ramón de Campoamor el 11 de febrero de 1901 se incumplió también su voluntad de ser enterrado «con la mayor sencillez» ${ }^{20}$. De hecho, a los dos días apareció en la Gaceta el real decreto por el cual el Estado asumía la organización del evento ${ }^{21}$. La justificación del Estado al admitir esa responsabilidad vino dada, en ambos casos, por la trascendencia de los personajes que a su muerte dejaban de ser unos particulares para convertirse en sujetos sociales, en la personificación de la patria, al haber entrado en el panteón de los inmortales de la cultura nacional.

En el caso de Zorrilla, además, por su carácter de poeta popular, se añadió un elemento que fue muy difundido por la prensa: «todos sienten que han perdido algo amado». Se creaba así una sensación de orfandad compartida por todos. La gran familia nacional había perdido a su vate y por tanto, el duelo era colectivo. La familia privada quedaba relegada al ámbito estrecho de la casa. Si a eso se le añade que Zorrilla no tuvo hijos, pero que dejaba a una viuda y a dos niñas, parientes de su esposa, que vivían con él, el sentido de protección del colectivo nacional hacia la familia se incrementaba de forma considerable 22 .

De este modo, se conjugaban los deseos del Estado de capitalizar la ceremonia y la necesidad popular de sentir el dolor de la muerte del poeta como algo propio. Los sentimientos colectivos fueron reforzados a través de la información de la prensa, que proporcionó datos acerca de los últimos momentos del poeta, sobre cómo fue su muerte en su casa de la calle de Santa Teresa, incluso sobre cómo era su casa, de cuya decoración se describieron aquellos objetos que por razón de la fama del poeta resultaban conocidos al lector (las coronas de su homenaje como poeta nacional, el retrato del emperador Maximiliano de México, etc.). Se dijo, no sin intención, que estancias

19 La Correspondencia de España (29-1-1893).

${ }^{20}$ La Época (12-2-1901).

21 «Real decreto disponiendo que los gastos de la conducción y entierro del cadáver de D. Ramón de Campoamor sean costeados por el Estado», Gaceta de Madrid, (13-2-1901).

22 Sobre la vivencia social de la muerte: ARIÈS, 1983 (1977). VOVELLE, 1983. 
como la sala de la casa «estaba decorada con la sencillez propia de la clase media» ${ }^{23}$. A través de este comentario se insistía una vez más en el lugar común (por otra parte, completamente cierto) de la precaria situación económica del poeta, recalcando que no se hizo rico en su vida, que murió pobre, «no hay que decirlo», escribieron los periodistas. Por tanto, no podía acusársele de haberse aprovechado de su fama y de sus amistades, lo que contribuía a hacerlo más próximo al común de los ciudadanos ${ }^{24}$. Incluso antes del fallecimiento, el periódico El Liberal, con el que el poeta colaboraba asiduamente, fue proporcionando noticias acerca del agravamiento de su enfermedad, noticias basadas en los partes de los médicos que atendían al enfermo. En definitiva, correspondió a la prensa el papel de convertir la enfermedad y muerte del poeta en un evento social de primera importancia.

La capilla ardiente se instaló en la Real Academia Española, a diferencia de otros escritores contemporáneos, cuyas capillas se ubicaron en el Congreso, apostándose claramente por su vinculación con la política. En cualquier caso, la relación de Zorrilla con la Academia no fue tan estrecha como pudiera haber hecho sospechar la decisión de trasladar el cadáver allí. ${ }^{25}$ Sin embargo, la Academia era una de las instituciones oficiales vinculadas al mundo de la cultura y como el control del difunto había pasado a manos del Estado, le correspondía a ella protagonizar el inicio de los actos funerarios. La Biblioteca Nacional podría haber sido otra opción para ubicar la presentación de respeto a los restos mortales del poeta, pero ocupó un segundo lugar, limitándose a cerrar sus puertas respetando el luto. Ambas, en tanto que instituciones oficiales y representantes del Estado en las cuestiones de la cultura, iban a capitalizar y gestionar este tipo de ceremonias en el futuro, elemento que caracteriza a los actos culturales en la España contemporánea ${ }^{26}$. A este respecto, es interesante apuntar que, desde que se tuvo conocimiento de la situación crítica del poeta, el Ateneo de Madrid (institución cultural de carácter privado a la que Zorrilla se hallaba muy vinculado) había decidido habilitar su salón de

23 La Correspondencia de España (24-1-1893).

24 Zorrilla no consiguió una ayuda del Estado en forma de pensión vitalicia hasta la edad de 70 años (Gaceta de Madrid, 22-1-1887) por mediación de la Asociación de Escritores y Artistas (PORPETTA, 1986: 117 y 155).

25 Zorrilla fue nombrado académico por primera vez en 1848, pero como no llegó a leer el discurso de ingreso, no formó parte de la corporación. El segundo nombramiento tuvo lugar tras la propuesta del marqués de Valmar, Manuel Cañete y Gaspar Núñez de Arce en junio de 1882. A la altura de octubre de 1882 Tamayo y Baus, el secretario de la RAE, conminó al autor a redactar su discurso de ingreso, que no fue leído hasta el 31 de mayo de 1885 en el paraninfo de la Universidad Central (Correspondencia diversa, Archivo de la RAE, Expediente de José Zorrilla, legajo 21, expediente 6).

26 D. Handelman señala que en los rituales modernos, las agencias burocráticas del Estado juegan un papel primordial (HANDELMAN, 1990). 
cátedras para convertirlo en la capilla ardiente. Según la prensa, la Academia se adelantó y una comisión de la misma se presentó en la casa del finado a las 8 de la mañana del día 23 (día del fallecimiento) con objeto de solicitar a la viuda el permiso para trasladar el cadáver y encargarse de la ceremonia ${ }^{27}$. La versión ofrecida por la propia Academia es muy distinta. Al parecer, cuando la familia comprobó el estado crítico del enfermo, envió a Esteban Escobar (sobrino de Zorrilla) y a Emilio Ferrari (amigo del poeta) a hablar con Manuel Tamayo y Baus, que era el secretario de la institución, para que la Academia se encargara del entierro ${ }^{28}$. La explicación de esta discrepancia, y la opción de la familia por la RAE, puede estar en el ofrecimiento que hizo esta institución de pagar los gastos del entierro y del funeral. La familia de Zorrilla no podía afrontar los gastos derivados de un funeral de tales características ${ }^{29}$. La organización de todos los eventos relacionados con el entierro y los funerales estuvo en manos de una comisión de la RAE formada por José Castro y Serrano, el padre Juan Mir Noguera y Antonio María Fabié.

La capilla ardiente se habilitó en el salón de actos de la Academia con las habituales colgaduras negras y crespones en las paredes. Al difunto se le colocó en un túmulo con un crucifijo entre las manos. Al lado de dicho túmulo, un altar para las misas que se le habrían de decir. De este modo, se empezaba a completar la mixtura de funeral cívico y funeral católico que tan presente estuvo en este tipo de ceremonias en la España del siglo XIX y buena parte del $\mathrm{XX}^{30}$. La mezcla de elementos civiles y religiosos se observa hasta en la

27 El Liberal (24-1-1893).

28 COTARELO, IV (Madrid, 1917): 15. Junta del 26 de enero de 1893, Archivo de la RAE, libro de actas $n^{\circ} 34$ y Notas de Esteban Escobar a la RAE el mismo día del fallecimiento, Archivo de la RAE, Expediente de José Zorrilla, legajo 21, expediente 6. Otras instituciones, como el Ayuntamiento de Madrid, se limitaron a condolerse públicamente y, a propuesta del concejal republicano Ramón Chíes, a aprobar la dedicatoria de una placa conmemorativa con un busto del poeta en el espacio urbano (Sesión de la Junta Municipal del 24-1-1893, Archivo de Villa, Actas del Ayuntamiento de Madrid, R. 497/86). Resulta curioso que la iniciativa de homenajear al «poeta de la tradición» procediera de Ramón Chíes, uno de los fundadores de las Dominicales del Libre Pensamiento.

29 De hecho, la RAE encargó a Menéndez Pelayo seleccionar una serie de poesías del autor fallecido para formar un libro que sería publicado a su cargo cuyo producto iría a parar a la viuda. El título fue Poesías escogidas y se editó en 1894 (Sesión del 9 de febrero de 1893, Archivo de la RAE, libro de actas $\left.n^{\circ} 34\right)$. La Academia realizó un gran esfuerzo económico al asumir estos pagos, pues por esas fechas se encontraba publicando las obras de Lope de Vega y en plena construcción del nuevo edificio de la calle Felipe IV, que se inauguraría en 1894.

30 Es interesante resaltar, a este respecto, cómo, ya en los años 60 y sobre todo a partir del Sexenio, comienzan a plantearse serios problemas con aquellos personajes con una clara vocación laicista, que pidieron funerales civiles. En este sentido, los choques entre la Iglesia y el Estado, por un lado, y los partidarios de una secularización efectiva encontraron en el tema de los enterramientos un nuevo campo de batalla. Véase: CRUZ, 2009: 73-105; UCELAY DA CAL, 2009: 129-169. Directamente asociada a esta cuestión está la de los cementerios civiles. 
dualidad de oraciones fúnebres que se habían previsto. La civil corrió a cargo de Castelar y se pronunció en la sesión de la Academia del día 26 de enero. La oración religiosa se había encargado al padre Florencio Jardiel quien, al parecer, no tuvo tiempo de prepararla ${ }^{31}$.

Pese a que después el protagonismo de la institución perdió peso en la procesión cívica y en el entierro, su papel no se desvaneció en el proceso de recordatorio del fallecido, ya que la Academia convocó a los amigos del poeta en los funerales que encargó y costeó en la iglesia de Santa Bárbara de Madrid para la primera mitad del mes de febrero, funerales que tratarían, una vez más, de reivindicar el carácter literario de la fama del difunto por medio de la presencia de ilustres escritores y artistas como Francisco Asenjo Barbieri, Juan Valera, Menéndez Pelayo, Federico Madrazo, etc., pero también su condición de poeta nacional, como puede verse en el listado de instituciones y personas invitadas al evento ${ }^{32}$. El carácter nacional del poeta quedó también inscrito en el periodo de tiempo que duró su estancia en la Academia a través de elementos como coronas con los colores de la bandera, bandas con insignias como «homenaje de la Patria a su preclaro hijo», la escolta de la Guardia Civil y la visita de ilustres personajes del mundo político e intelectual, etc.

\section{Procesión Cívica Y ENTIERRo}

Una de las partes más importantes del ritual funerario es la traslación del cadáver desde la capilla ardiente al cementerio. Constituye esta parte de la ceremonia el capítulo en el que se verifica de forma más clara la exhibición pública del fallecido. La preparación de esta sección de la ceremonia se convirtió en algo complejo pues requería la elección de un itinerario acorde a las características de su protagonista y, sobre todo, a las intenciones de las autoridades. Además del itinerario, se trataba de coordinar y situar a las representaciones de distintos colectivos sociales que habían manifestado su deseo de acompañar al cortejo. Un tercer elemento a tener en cuenta lo constituía la calidad social de las personas que formarían el duelo, es decir, aquellos personajes públicos que encabezarían la marcha de la comitiva. Ciertamente, no era lo mismo organizar unas exequias para un prohombre de la patria, un político, que para un artista, por lo que los matices eran importantes.

Se planteó, a este respecto, una cierta polémica, pues el gobierno de Sagasta no quiso que se tributasen honras militares al fallecido por tratarse de un

31 Archivo de la RAE, libro de actas $\mathrm{n}^{\circ}$ 34, sesión del 9 de febrero de 1893. Sobre la tradición de las oraciones fúnebres: BONNET, 1997, t. II: 1831-1854.

32 Listado de instituciones y personas invitadas a los funerales de José Zorrilla, Archivo de la RAE, Expediente José Zorrilla, legajo 21, expediente 6. 
civil y por no existir precedentes. En anteriores entierros de hombres de letras que habían sido ministros, jefes de gobierno o presidentes de alguna de las dos cámaras, sí se habían celebrado honras militares, pero por su condición de hombres políticos. Así sucedió con Martínez de la Rosa o con Alcalá Galiano. La prensa lanzó duras críticas a esta decisión, acusando al gobierno de tratar al difunto como «una de las tantas medianías encumbradas por la política» ${ }^{33}$. En realidad, lo que revelaba esta encendida polémica era la carencia de un ritual mortuorio para los grandes hombres que no hubieran desempeñado puestos políticos o militares (artistas, científicos, eruditos...). Se habían comprobado las posibilidades de instrumentalización política de tales ceremonias, pero no se había establecido un procedimiento, una liturgia social. Los únicos rituales que se podían asimilar eran los militares, que sí se tributaron, como se ha dicho antes, a personajes como Francisco Martínez de la Rosa. En su caso, recibió el homenaje de mayor categoría, que se aplicaba incluso a los infantes de España: el de capitán general con mando de plaza y ejército ${ }^{34}$. La documentación de la RAE revela que para el caso de Zorrilla se buscó en el entierro de Quintana un modelo a imitar o al menos una línea a seguir. A este respecto, el secretario de la Academia, Tamayo y Baus se puso en contacto con Eduardo Vincenti, director general de Instrucción Pública. Ambos revisaron la prensa y la Gaceta de 1857 para ver cómo se había procedido entonces y concluyeron que «no hay precedentes relativos a la expedición de un decreto», por lo que Sagasta, presidente del gobierno, Moret, ministro de Fomento, y la RAE decidieron el procedimiento y las instituciones y personas que habrían de ser invitadas. ${ }^{35}$

El entierro de Zorrilla tuvo lugar el día 25 de enero, miércoles. La importancia que se otorgó al acontecimiento vino dada por la presencia de un delegado de la reina regente. En un principio, se anunció que este delegado sería el duque de Rivas (hijo), quien había coronado a Zorrilla como poeta nacional

33 El Imparcial (25-1-1893).

34 «Real decreto disponiendo se tributen á D. Francisco Martínez de la Rosa los honores fúnebres que la Ordenanza señala para el Capitán General de ejército que muere en plaza con mando en Jefe», (Gaceta de Madrid, 9-2-1862). Consistía este homenaje en un nutrido acompañamiento de fuerzas militares que se situaban al inicio y al final de la comitiva y que eran dispuestos por la ordenanza al respecto. En el caso de Martínez de la Rosa, cuando el cortejo se detuvo en el inicio del camino que llevaba a la Sacramental de San Sebastián (donde iba a ser enterrado) se dispararon veinte cañonazos (el mismo número al sacar el féretro de la casa mortuoria). Mientras se colocaba el cadáver en el nicho, las dos compañías destinadas en la parte de atrás del cementerio hicieron las descargas de ordenanza (La Correspondencia de España, 11-2-1862). El mismo homenaje se hizo a Abelardo López de Ayala (La Iberia, 3112-1880).

35 Cartas cruzadas entre Manuel Tamayo y Baus y Eduardo Vincenti entre el 23 y el 24 de enero de 1893, Archivo de la RAE, Expediente de José Zorrilla, legajo 21, expediente 6. 
en 1889 , en nombre de la regente. Sin embargo, ante la enfermedad de éste la regente optó por Isidoro María de Hoyos y de la Torre, segundo marqués de Hoyos $^{36}$. Le acompañaron presidiendo el duelo los ministros de Estado, Gobernación, Hacienda, Guerra y Ultramar; Cánovas del Castillo, como presidente de la Academia de Jurisprudencia; así como Martínez Campos, Pidal, el padre Mir y Tamayo y Baus. Las cintas del féretro fueron llevadas por un grupo de personajes que también representaban la unión de la política y las letras: Eduardo Vincenti (director de Instrucción Pública, representando al gobierno); Menéndez Pelayo (representando a la Academia de la Historia); Julio Vargas (presidente de la Asociación de Escritores y Artistas); el marqués de Valdeiglesias (por la prensa ${ }^{37}$ ); José Antonio López Pintó (en representación del Ayuntamiento de Valladolid y, por extensión, de todos los ayuntamientos de España) ${ }^{38}$; José Echegaray (por el Ateneo) ${ }^{39}$; Juan Valera (por la Academia Española); y Antonio Vico (por los actores).

La comitiva fúnebre salió de la calle Valverde, sede de la Academia, acompañada por el clero de las iglesias de San Ildefonso y Santa Bárbara y custodiada por la Guardia Civil. Todo ello dice mucho de las características del funeral: las fuerzas tradicionales como escoltas del poeta de la tradición, dentro de una sobriedad y una moderación muy propias del tono burgués de la sociedad del momento ${ }^{40}$. Junto a ellas, porteros del ministerio de Fomento, de la Academia, del Ateneo de Madrid, doce marineros del Museo Naval y agentes del orden público ${ }^{41}$. Las diversas delegaciones que acompañaron al féretro representaron a un amplio espectro de la sociedad. Se congregaron grupos de

36 La Correspondencia de España (23-1-1893) y COTARELO, IV (Madrid, 1917), 17.

37 Se trataba de Alfredo Escobar Ramírez, que sucedió a su padre Ignacio Escobar y López de Hermosa, en la dirección de La Época, periódico de orientación conservadora. La RAE había designado al director de este periódico como representante de la prensa por ser La Épo$c a$ el diario más antiguo de Madrid. Sin embargo, Escobar y los directores de los periódicos más importantes de la capital prefirieron que asistiera el decano de todos ellos: el marqués de Santana, que finalmente no acudió por razones de salud (Nota del marqués de Valdeiglesias a Tamayo y Baus, fechada el 24 de enero de 1893, Archivo de la RAE, Expediente José Zorrilla, legajo 21, expediente 6).

38 La prensa ofrece informaciones erróneas acerca de Pintó, señalando que era alcalde de Valladolid. En el momento del fallecimiento del poeta, el alcalde era José Hornedo Huidobro. Los dos representantes de la ciudad en el acto fueron el mencionado Pintó y César Silió, por decisión del propio alcalde comunicada al pleno del ayuntamiento (Acta de la sesión extraordinaria del pleno del Ayuntamiento de Valladolid, 25-1-1893, Archivo Municipal de Valladolid, caja 7073).

39 La información que ofrece la prensa difiere de la documentación de la RAE, ya que en el expediente de José Zorrilla hay una carta del Ateneo de Madrid designando a su presidente, Gumersindo de Azcárate, para portar una de las cintas del féretro.

40 ORDÓÑEZ VERGARA 15 (Málaga, 1993), 24.

${ }^{41}$ La Guardia Civil fue el único cuerpo militar que como tal asistió al homenaje. Como se ha dicho antes, no se le tributaron honores militares. 
estudiantes de derecho, medicina y filosofía y letras (con los que Zorrilla, que no terminó sus estudios universitarios, no había tenido un trato especial), seguidas por los landós que transportaban las coronas enviadas por editores (con los que el poeta no mantuvo buenas relaciones), actores (los de los teatros Apolo y de la Comedia), municipios (Valladolid, Murcia), periódicos y revistas (El Imparcial, Blanco y Negro, La España Moderna, etc.), instituciones educativas (la Universidad Central), instituciones culturales (el Ateneo de Madrid, el Círculo Artístico y Literario), asociaciones de escritores (la Asociación de Escritores y Artistas), amigos (Emilio Ferrari, el doctor Letamendi, José Muro...) y un largo etcétera. Trescientos coches más les seguían con personajes políticos, aristócratas, artistas, escritores, etc. ${ }^{42}$

El recorrido había sido previamente diseñado para que resultase lo más directo posible por dos razones más que evidentes: evitar colapsar el centro de la ciudad y controlar la acumulación de personas. El gobernador había ordenado la suspensión de la circulación de tranvías desde la una de la tarde, pues la previsión era que el cortejo saliese de la Academia a las dos. Dicha orden indicaba ya de forma clara que se esperaba la congregación de una multitud de asistentes. El itinerario siguió la ruta de las calles Valverde, Desengaño, Fuencarral, Montera, Puerta del Sol, calle Mayor para desembocar en la Cuesta de la Vega y de allí dirigirse al cementerio de San Justo. Aunque en la actualidad estas calles no resultan lo amplias que pudiera haber requerido un acto de tales características, sí lo eran en el siglo XIX, por lo que a pesar de la muchedumbre que se esperaba, el orden público podría ser mantenido en todo momento. No hay que olvidar que, como se comentará después, la presencia en las calles de masas de gente, aunque fuera para el entierro de un personaje como Zorrilla (poco sospechoso de atizar pasiones políticamente peligrosas), no dejaba de generar recelos entre las autoridades. Curiosamente, en el recorrido por la ciudad se evitó hacer paradas delante de los teatros, como era costumbre con los autores teatrales y como se había hecho en 1879 con el también poeta Adelardo López de Ayala. La excusa fue evitar demoras en la traslación del cadáver al cementerio, lo que no tenía gran justificación, ya que el cortejo sí realizó una parada en la calle Mayor, al lado de la plaza de la Villa, sede del Ayuntamiento de Madrid, y en la Cuesta de la Vega, ante la iglesia de la Almudena ${ }^{43}$. La primera se trató de una detención para que las autoridades municipales rindiesen homenaje al poeta colocando una corona

42 Para conocer la larga nómina de personajes, véase el n ${ }^{\circ}$ el 26 de enero de 1893 de $L a$ Correspondencia de España.

43 La Academia había recibido indicaciones del ministro de Fomento, Segismundo Moret, de no realizar paradas en el discurrir de la comitiva, según comunicaron los miembros de la comisión organizadora al pleno de los académicos en sesión de 26 de enero de 1893 (Sesión de 26 de enero de 1893, Archivo de la RAE, libro de actas n 34). 
en el féretro y para que la banda de música del asilo de San Bernardino interpretase la marcha fúnebre «iDescanse en paz!». En la segunda detención, la presidencia del duelo se situó frente a la iglesia para presenciar el paso de la comitiva y como dice, no sin ironía, el cronista de La Correspondencia de España, «quedando por cierto el cadáver algún tanto olvidado». Allí la orquesta y coro del Teatro Real ejecutaron piezas musicales como la «Marcha fúnebre» de Chopin. En este tipo de eventos, la música jugaba un papel primordial por su capacidad para crear el ambiente emocional adecuado. En el caso que nos ocupa, la comitiva se detuvo a escuchar no sólo estas dos ocasiones mencionadas, sino también la interpretación que durante el recorrido realizó la banda de música del regimiento del segundo de Ingenieros al mando de Eduardo López Juarranz ${ }^{44}$.

Las crónicas del acontecimiento narran la presencia de la muchedumbre en el cortejo de forma ambivalente. Por una parte, se insiste una y otra vez en la aglomeración de personas para destacar el carácter representativo del fallecido, en el aprecio popular del que gozaba entre todas las clases sociales, lo que justificaba el despliegue de medios que habían realizado las instituciones en su homenaje y en la necesidad de una ceremonia de tales características. La prensa comentó que más de 50.000 personas habían pasado por la capilla ardiente $^{45}$. Se dice, por ejemplo:

...desde la cuesta de la Vega hasta el cementerio, la gente se agolpaba en prodigioso número a uno y otro lado del camino. Parecía que Madrid entero se había despoblado para rendir con su presencia un tributo de admiración al vate castellano ${ }^{46}$.

Igualmente, se califica favorablemente el proceder de esa multitud al decir que ha mostrado un comportamiento cívico y respetuoso: quitarse los sombreros y gorras al paso del féretro y mantener un absoluto silencio. En ese momento, la multitud quedaba dignificada por su conducta. Sin embargo, se recela de esa misma muchedumbre. La prensa contaba cómo, a la llegada al cementerio, la gente «había asaltado el camposanto» y las fuerzas del orden se vieron obligadas a actuar ante el desorden producido:

...en el momento de llegar allí el cadáver, la confusión fue inmensa: la gente se agolpaba sin respetar nada, atropellando los sepulcros y echando por el suelo plan-

44 En este caso, se ejecutaron las piezas «iPobre!», «Ha muerto» y «Mercedes», del propio maestro Juarranz (La Época, 25-1-1893).

45 El Liberal, 25-1-1893.

46 La Correspondencia de España, 26-1-1893. 
tas y árboles. El Sr. Pidal tuvo que defender entonces, a brazo partido, al anciano conde de Cheste, pues la ola humana todo lo invadía ${ }^{47}$.

¿Curiosidad o verdadero aprecio por el poeta? Éste parece ser el dilema que intrigaba al cronista acerca de la gran afluencia de gente al entierro. Similar perplejidad asaltaba al periodista de La Correspondencia de España al comentar las actitudes de las personas que pasaron a ver la capilla ardiente:

Unos murmuraban fervientemente oraciones por el eterno descanso del inspirado vate; otros daban expansiones a su dolor y lo traducían en copioso llanto; y otros dibujaban en sus semblantes extrema curiosidad por ver aquella noble figura, cuya gloria proclama un pueblo entero ${ }^{48}$.

En definitiva, lo que se trasluce es una elitista duda acerca de la capacidad de la masa de tener sentimientos elevados. Al parecer, la confusión en el cementerio se produjo cuando la gente vio adelantarse a Castelar. Creyendo que iba a pronunciar uno de sus discursos, los asistentes se abalanzaron hacia delante para oírle mejor ${ }^{49}$. Estamos, pues, ante una concepción del acontecimiento como espectáculo.

Finalmente, Zorrilla fue enterrado en el cementerio de San Justo, en el patio de Santa Gertrudis, en la sepultura número $142^{50}$. Una vez más, esta decisión no fue inocente, políticamente hablando. En la cláusula tercera de su testamento, el escritor había dejado dicho que quería que se le inhumase en su tierra natal, Valladolid. El ayuntamiento de esta ciudad había encargado a los dos comisionados en Madrid, César Silió y José Antonio Pintó Lara, que reclamasen el cuerpo para que fuera enterrado en el cementerio local ${ }^{51}$. Sin embargo, sus deseos no fueron atendidos y el Gobierno Civil de la provincia comunicó al Ayuntamiento de Valladolid, a instancias del subsecretario del Ministerio de la Gobernación, que el cuerpo no podía ser inhumado (al haber sido enterrado ya en Madrid) hasta que no pasasen dos años, en función de la real orden de 21 de marzo de 1848, lo que tuvo que ser aceptado finalmente

47 La Época (25-1-1893). Extrañamente, el marqués de Rozalejo, en su biografía el conde de Cheste, no hace la menor mención a la participación de éste en la organización del entierro de Zorrilla. El conde de Cheste era en esos momentos el director de la Real Academia Española (lo fue entre diciembre de 1875 y 1906, año de su muerte).

48 La Correspondencia de España (23-1-1893).

49 El Imparcial (26-1-1893).

50 Certificado de enterramiento expedido por la Secretaría de la Archicofradía Sacramental de San Miguel, Santa Cruz, Santos Justo y Pastor y San Millán, Archivo de la RAE, Expediente José Zorrilla, legajo 21, expediente 6.

51 Acta de la sesión extraordinaria del pleno del Ayuntamiento de Valladolid del día 25 de enero de 1893, Archivo Municipal de Valladolid, caja 7073. 
por Valladolid 52 . La disputa por la posesión del cuerpo evidenciaba una realidad: el poeta nacional no podía ser enterrado más que en la capital de la nación. Eso parecía indiscutible para todos los implicados, incluida la propia ciudad de Valladolid, que si bien planteó desde muy pronto los deseos del finado, no puso en marcha más trámites para que fuera obviada la real orden mencionada. Sin embargo, y dado el hecho de que la posesión de los restos de un fallecido ilustre empezaba a convertirse en un elemento importante para la configuración del imaginario local, el ayuntamiento de la ciudad castellana concibió la idea de que los restos fueran trasladados a Valladolid pasado un tiempo prudencial, como se verá después. Evidentemente, el tiempo suficiente como para que la estela del acontecimiento se hubiese borrado y pudiese comenzar a tener una nueva significación por la cual el poeta nacional empezara a adquirir perfiles de ilustre conciudadano, gloria nacional, pero con arraigo local.

En los funerales de Zorrilla hay otro elemento de importancia que viene dado por su condición de gran acontecimiento y por la gran afluencia de personas. La sensación de estar enterrando a un gran hombre de la patria iba más allá de la política para entrar en los sentimientos y recuerdos de todos. Cada uno de los presentes creía en la necesidad de participar en la ceremonia, pero no sólo eso, sino también se generaba el deseo de conservar algo de aquel «gran momento» vivido por todos en comunidad, momento en el que los lazos colectivos de pertenencia a dicha comunidad se habían reforzado por un hecho luctuoso que afligía a todos, indistintamente de la clase social a la que se perteneciera. Todos sienten la muerte del poeta, a todos afecta, y todos tienen deseos de conservar un recuerdo. En la naciente sociedad de masas (muy en pañales en España, ciertamente) ese recuerdo no sólo era emocional, sino que había de ser material, para que en su contemplación el ciudadano afianzara su compromiso colectivo y para que, de cara al conjunto, quedara patente su presencia en un momento considerado crucial por la colectividad: «yo estuve allí». Ese recuerdo se plasma en la posesión de un objeto relacionado con el acontecimiento. En el caso que nos ocupa, la prensa nos cuenta cómo, al paso del cortejo por la calle Desengaño fueron lanzadas miles de hojas impresas con una breve composición poética escrita por Eduardo Albaladejo, hojas que fueron atesoradas por el público ${ }^{53}$. Más significativo aún fue

52 Carta de Román Martín, del Gobierno Civil de la Provincia de Valladolid al alcalde de la ciudad (18.3.1893), Archivo Municipal de Valladolid, caja 7073. La real orden aludida establecía que, por razones sanitarias, los cuerpos no se trasladasen hasta al menos haber pasado dos años de su inhumación, salvo que hubieran sido embalsamados. Actualizaba así las reales órdenes de 27 de marzo de 1845 y 21 de febrero de 1846 (Gaceta de Madrid, 21.3.1848).

53 La Época (25-1-1893). La composición dice así: «Improvisación. Murió el canoro vate, lumbrera de la historia / El que cantó a Granada con estro sin igual / Pero sus cantos bellos, 
el hecho de que en la Puerta del Sol se distribuyesen fotografías de Zorrilla, como indica La Correspondencia de España del día 26. Se trataba de fotografías del poeta cuando estaba vivo. En su caso no encontraremos las imágenes del artista en el lecho de muerte, como sí sucedió con Victor Hugo. Todo ello ha de ser considerado el paso previo a la fabricación y venta de máscaras de la cara de Zorrilla, continuando una tradición muy propia del siglo XIX. La fabricación de máscaras de artistas o de otros personajes encubría, en realidad, el deseo de atrapar el instante antes de que el cuerpo comenzase su proceso de descomposición, ganarle al tiempo una instantánea del insigne personaje (o de la persona amada, en el caso de individuos particulares) antes de que desapareciese para siempre en su forma física ${ }^{54}$. La máscara de Zorrilla fue realizada por el escultor Aurelio Rodríguez Carretero, quien después se serviría de ese mismo molde para la estatua del poeta que se encuentra actualmente en Valladolid ${ }^{55}$.

\section{LUGARES DE LA MEMORIA}

La consulta de la prensa de la época revela el deseo de muchas localidades de España de sumarse al gran acontecimiento por medio de diversas ceremonias. Las más frecuentes fueron, dado el carácter del acontecimiento, religiosas, es decir, la celebración de exequias. Por otra parte, y ante la profesión literaria del finado, las instituciones culturales de estas localidades se volcaron en la realización de homenajes para sancionar la naturaleza unánime del duelo, para significar que el poeta era, efectivamente, el poeta nacional, el creador en el que todas las ciudades y pueblos de España se podían ver reflejados. Así, los ayuntamientos de Alicante o Segovia, anunciaron que sufragarían exequias por su alma; el Círculo Católico de Obreros de Murcia indicó que celebraría una velada literaria en honor del poeta; el Ateneo de Madrid reunió a escritores y artistas en diversas ocasiones para homenajear al difunto, etc. La profusión de iniciativas en este sentido evidenciaba dos hechos: por un lado, la voluntad de no quedar al margen del «gran evento»; por otro, el deseo

\footnotetext{
y su renombre y gloria, / Proclaman a Zorrilla poeta sin rival / Ya doblan las campanas, ya todo es desconsuelo / Y cúbrese la patria con fúnebre crespón... / ¡Quizá Zorrilla el acto contempla desde el cielo / Y envía a nuestra España su amante bendición!». Probablemente no fuera la intención del ahora ignorado Albaladejo la de hacerse famoso a través de su poesía, pero su acción trae a la memoria la forma en la que el propio Zorrilla se dio a conocer en el mundo literario de su tiempo con su recitación en el entierro de Larra. Algunas de estas octavillas fueron después enviadas a la Real Academia Española para su custodia (Archivo de la RAE, Expediente de José Zorrilla, legajo 21, expediente 6).

54 GUILLÉN, 2007: 284.

55 CANO DE GARDOQUI GARCÍA, 2000: 52.
} 
de llevar la iniciativa en las celebraciones. En este sentido, y en tanto que organizadora de las fiestas de la coronación en 1889, Granada se consideró obligada a no quedar atrás en estos homenajes póstumos al poeta. El periódico El Defensor de Granada, que apareció con orla de luto, recordó aquellos festejos, publicó numerosas cartas entre el poeta fallecido y el director del diario (Luis Seco de Lucena) y envió una corona ${ }^{56}$. Por su parte, el Liceo Artístico de Granada, artífice de las ceremonias de 1889 , se reunió en sesión extraordinaria para hacer público su sentimiento y enviar un telegrama de pésame a la viuda.

Sin embargo, detrás de todas estas iniciativas late el anhelo de materializar y perpetuar en el tiempo el reconocimiento al artista. Se trataría, en última instancia, de consolidar en el espacio físico de la ciudad la huella de alguien a quien se siente como propio, como el cantor de la esencia popular. Si en la casa se recuerda al familiar desaparecido mediante fotografías o mediante la presencia de objetos que le pertenecieron, en el espacio público que corresponde al hogar de la nación, es decir, la ciudad, otros elementos materiales han de recordar al prohombre y perpetuar su memoria para la posteridad. Estaríamos hablando aquí de la erección de monumentos y de la dedicación de calles al personaje en cuestión ${ }^{57}$. A este respecto se observa también la intención generalizada por renombrar las vías públicas o por otorgar el nombre del poeta a los nuevos espacios producto de las ampliaciones urbanísticas. Así sucedió en Cádiz, que cambió el nombre de la antigua calle del Puerto por el de Zorrilla ${ }^{58}$, o el de Madrid, donde por acuerdo municipal se cambió la denominación de la antigua calle del Sordo por la de Zorrilla el 10 de febrero de $1893^{59}$.

Sin embargo, la acción más destacada fue la erección de un monumento en su nombre. Una vez más, en esta cuestión el investigador se encuentra con una profusión de iniciativas que revelan una gran dispersión en los proyectos. No puede decirse que el Estado representara aquí un papel muy destacado, pues el protagonismo corrió a cargo de ayuntamientos e instituciones culturales privadas. Por razones económicas o por desinterés, no mostró el Estado deseos de capitalizar el proceso de negociaciones y recaudación de dinero para llevar adelante la construcción del monumento. También puede explicarse

56 El Defensor de Granada (25-1-1893).

57 La erección de estatuas a los hombres de letras no ha sido en España una iniciativa tan fecunda como en otros países. De esto se lamentaba Clarín en 1891 hablando de la recién levantada estatua a Jovellanos en Gijón, nada menos que ochenta años después de su muerte (LISSORGUES, 11, Salamanca 2010: 146).

58 La Correspondencia de España (27-2-1893).

59 Sesión de la Junta Municipal del 10-2-1893, Archivo de Villa, Actas del Ayuntamiento de Madrid, R. 497/86. Sin embargo, hasta 1916 no se colocó una lápida de recuerdo en su casa de la calle de Santa Teresa número 2. 
esta aparentemente extraña carencia de iniciativa por el hecho de que una vez producidos los funerales, el personaje dejaba de tener un interés político concreto. Finalmente, y a pesar de que una de las primeras comisiones recaudatorias se creó en Burgos ${ }^{60}$ y la otra fue organizada por el Ateneo de Madrid ${ }^{61}$, el protagonismo fue recayendo, poco a poco, en la ciudad de Valladolid.

Aunque la ciudad ya había nombrado al poeta «cronista de Valladolid» ${ }^{62}$, cuando se planteó la coronación de Zorrilla en 1889, Valladolid fue sobrepasada por el empuje de Luis Seco de Lucena y la ciudad de Granada, perdiendo el protagonismo que le hubiera podido corresponder por ser la localidad de nacimiento de Zorrilla. Sin embargo, en esta ocasión su ayuntamiento catalizó las actividades de otros municipios y sobre todo, las iniciativas privadas de teatros o sociedades culturales, actuando el Ateneo de Madrid como intermediario. Se celebraron veladas en ateneos y liceos; se hicieron funciones especiales en teatros de diversas ciudades españolas; y sociedades como la Asociación de Escritores y Artistas, que abrió una suscripción entre sus socios. El Ayuntamiento de Valladolid actuó con rapidez y, aparte de celebrar las consabidas exequias en la catedral, dispuso una partida económica para adquirir la casa en la que nació el poeta y convertirla en un museo que contendría ejemplares de sus obras y los objetos que utilizó en su vida cotidiana ${ }^{63}$. Facilitó la tarea la donación que la viuda del poeta realizó de diversas piezas del mobiliario doméstico, como la cama en la que murió Zorrilla, la mesa en la que escribía, el sillón en el que se sentaba habitualmente, las diversas coronas y otro tipo de adminículos de uso diario que actualmente se pueden ver en la Casa-Museo de Zorrilla en Valladolid. ${ }^{64}$ Al igual que sucedió con la distribu-

60 La Correspondencia de España (16-4-1893).

${ }^{61}$ La Época (9-2-1893). La comisión del Ateneo estuvo formada por el vizconde de Campogrande (representando a las reales academias); el conde de las Navas (por las reales sociedades); Antonio Sánchez Moguel (por las universidades); Pedro Antonio Santonja (por las escuelas); Carlos Fernández Shaw (por la Diputación de Madrid); Emilio Ferrari (por los teatros); Manuel Sainz y el conde de Casal por los círculos; y Conrado Solsona y Luis Morote por la prensa.

${ }_{62}$ Archivo Municipal de Valladolid, serie 2414, Expedientes de nombramientos, CH 254-33, legajo 32 y caja 254-3 (9).

63 Acuerdos del pleno del Ayuntamiento de Valladolid, 1-4-1893, Archivo Municipal de Valladolid, CH 360-29. Pese a los intentos del Ayuntamiento, no se completó la compra de la casa hasta 1918 cuando, tras la celebración del centenario del nacimiento del poeta en 1917, se firmó la escritura (Copia de ratificación de la escritura de venta, 20-8-1918, Archivo Municipal de Valladolid, caja 429, fol. 52-53). En este edificio se halla en la actualidad la Casa-Museo de Zorrilla. Sobre la Casa-Museo: URREA FERNÁNDEZ, 43 (Valladolid, 2008): 57-64.

${ }^{64}$ La donación de la viuda se hizo a cambio de que ésta pudiera percibir una pensión del Ayuntamiento de Valladolid y una vivienda. En diciembre de 1893 doña Juana Pacheco, viuda del poeta, se hallaba viviendo en un pueblo cercano a la capital castellana ya que aún no se le 
ción de octavillas con el poema de recuerdo en la procesión por las calles, o con el reparto de fotografías en la Puerta del Sol, nos encontramos nuevamente con un ejemplo del fetichismo del objeto.

Como la compra de la casa parecía dilatarse, se colocó una lápida conmemorativa en la fachada, ya que por el momento no se podía hacer otra cosa. El acto tuvo lugar el 28 de septiembre de septiembre de 1895 y consistió en una ceremonia que comenzó con una procesión cívica presidida por las autoridades locales. Detrás de esta comitiva se situó una carroza con los objetos personales del poeta donados por su viuda. Esta procesión cívica, con un paralelismo claro con la religiosa ofrecida en el entierro de Madrid, aunque de menores dimensiones, ahondaba en el carácter local del poeta y en la contribución de un natural de la ciudad a la grandeza artística de España. Así lo decían las cintas de las coronas de flores que se portaron: «Valladolid a Zorrilla» y «Zorrilla, gloria de España». La lápida había sido realizada por el escultor Dionisio Pastor Valsero ${ }^{65}$.

\section{VALLADOLID ASUME EL PROTAGONISMO}

El traslado de los restos del poeta a Valladolid tenía que convertirse en el gran acto de homenaje de la ciudad a su paisano. Es significativo que quienes gestionaron todo el proceso fueran el alcalde, Pedro Vaquero Concellón, y los tres escritores vallisoletanos que vivían en Madrid y que habían desempeñado el papel de representantes de la localidad en todos los homenajes que se hicieron a Zorrilla en la capital: Gaspar Núñez de Arce, Emilio Ferrari y Leopoldo Cano y Masas. De hecho, Núñez de Arce fue nombrado presidente de la «comisión encargada de la traslación de los restos de José Zorrilla». Ello es indicativo del carácter local que iba a ir tomando la figura del personaje. Todo el proceso, desde la apertura de la tumba hasta la inhumación en el cementerio de Valladolid, repitió los pasos ya dados en $1893^{66}$. La sepultura se abrió el 2 de mayo de 1896 y se trasladaron los restos al Museo Antropológico del doctor Velasco, situado en la plaza de Atocha de Madrid ${ }^{67}$. En el salón de este

había proporcionado dicha casa (Acta de la sesión del Ayuntamiento de Valladolid del 7-121893, Archivo Municipal de Valladolid, caja 7073).

65 Valsero ya había regalado al Ayuntamiento un busto del escritor cuando éste fue nombrado cronista oficial de la ciudad en 1887, momento en que se le encargó la confección de la lápida, que realizó también gratuitamente (CANO DE GARDOQUI GARCÍA, 2000: 47-49).

${ }^{66} \mathrm{La}$ narración detenida de todo este proceso en GONZÁLEZ GARCÍA-VALLADOLID, 1902 , t. III.

67 La Real Academia Española solicitó a la Archicofradía Sacramental de San Justo que mantuviera vacía la tumba del poeta en Madrid, lo que ésta aceptó si la Academia se hacía cargo de la lápida conmemorativa (Cartas cruzadas entre el presidente de la Archicofradia y 
museo se instaló una capilla ardiente. Asistieron de nuevo representantes de academias, instituciones oficiales, embajadas, prensa, etc. El siguiente paso consistió en el traslado del féretro a la Estación del Norte, acompañado otra vez por la Guardia Civil, un representante de la regente (el duque de Sotomayor), la banda de Ingenieros, la comisión vallisoletana, el Ayuntamiento de Madrid y un largo etcétera ${ }^{68}$. De nuevo, la multitud en la calle. Las consabidas detenciones del cortejo se produjeron esta vez ante el Palacio Real, a cuyos balcones se asomaron la reina regente, el príncipe Alfonso y las infantas. Llegados a la Estación del Norte, se instaló el féretro en un furgón decorado con paños negros guardado por los maceros del Ayuntamiento de Valladolid, y fue acompañado de otros tantos coches para conducir a la antigua capital de España a la numerosa comitiva. El viaje en tren fue algo accidentado, sobre todo para Zorrilla, pues como señala el cronista que vivió aquellos momentos:

Por fin, un mozo de tren que pasa junto a nosotros alumbrándose con una linterna, nos explica el siniestro. La cabeza de Zorrilla, del busto, o de la estatua en cartón de la Inmortalidad, se había hecho mil pedazos contra un saliente de la bóveda. El artilugio fúnebre en que iba el ataúd con los restos del poeta, removido y desequilibrado, tropezaba con el revestimiento del túnel ${ }^{69}$.

La organización del entierro en Valladolid evidenció también el protagonismo de lo político sobre lo cultural. La comitiva local esperó la llegada de los restos en la estación de tren y, una vez producida esta, se realizó el itinerario previsto. Se había diseñado un recorrido, como en Madrid, acorde con la categoría que se quería dar al acto, avanzando la comitiva por el Campo Grande, la zona nueva de la ciudad. La detención tuvo lugar, esta vez sí, ante los teatros Zorrilla y Calderón de la Barca. Finalmente, el poeta fue enterrado, aunque continuó recibiendo homenajes en diferentes centros culturales e instituciones de la ciudad. Sin embargo, lo interesante a este respecto fue la disposición del séquito. Delante del féretro se situaron las autoridades políticas, militares y religiosas que intentaron (y lograron) protagonizar la celebración: el duque de Sotomayor, en representación de la familia real; el conde de Tejada Valdosera, ministro de Gracia y Justicia, en representación del gobierno;

Antonio María Fabié en junio de 1896, Archivo de la RAE, Expediente de José Zorrilla, legajo 21, expediente 6).

68 A modo de curiosidad, puede señalarse que el Ayuntamiento de Madrid, que por esas fechas estaba preparando los actos conmemorativos del 2 de mayo, a la altura del 29 de abril aún no había decidido quiénes iban a ser sus representantes en la ceremonia. Lo que aprobó con mayor celeridad fue la «exención de pagos por derechos de traslación de cadáver para el caso de José Zorrilla» (Sesión ordinaria del pleno del Ayuntamiento del 29-4-1896, Archivo de Villa, Actas del Ayuntamiento de Madrid, R. 501/86).

69 GONZÁLEZ GARCÍA-VALLADOLID, 1902, III: 891. 
el cardenal Cascajares, arzobispo de Valladolid; el gobernador civil de la provincia; el obispo de Ávila; el comandante general del séptimo cuerpo del ejército; el presidente de la diputación provincial; el alcalde Pedro Vaquero; el rector de la Universidad literaria; y el decano del Colegio de Abogados. Detrás de este grupo, se situó al difunto en una carroza y detrás del difunto se ubicó a la familia (representada por Joaquín Arimón, sobrino del finado) y a los escritores e intelectuales vallisoletanos: Núñez de Arce, José Muro, Emilio Ferrari y Leopoldo Cano ${ }^{70}$. El discurso ante la tumba lo realizó el autor de los Recuerdos de la campaña de África.

Sin embargo, no terminaron aquí las andanzas funerarias de José Zorrilla. El traslado de sus restos a Valladolid en 1896 había impulsado en la ciudad el deseo de reivindicar las propias raíces a través del homenaje a sus ilustres conciudadanos, en la línea de la ola regionalista y localista que por aquellos años se extendía por España. El mismo día del entierro en Valladolid, el 4 de mayo, se había puesto la primera piedra de lo que iba a ser el Panteón de Vallisoletanos Ilustres, situado en el mismo Cementerio del Carmen ${ }^{71}$. En espera de que este edificio fuera terminado, el 28 de febrero de 1901 se cambiaron de sepultura los restos del poeta. Y finalmente, el 4 de abril de 1902, ya terminado el Panteón, se le depositó en el sarcófago donde reposa desde entonces ${ }^{72}$.

Poco antes de estos acontecimientos, se había instalado, el 14 de septiembre de 1900, la estatua que había realizado el escultor Aurelio Rodríguez Carretero. Esta estatua es la que se había financiado con la suscripción impulsada por el Ateneo de Madrid ${ }^{73}$. Si a través del entierro se habían revalidado los valores representados por el poeta, por medio de la erección de una estatua se consolidaba su memoria y su significado en el espacio público ${ }^{74}$. Su inauguración volvió a mezclar elementos religiosos y civiles, pues además de las diversas comisiones municipales y la comisión de organización, asistieron numerosos representantes de la Iglesia, como el ya citado cardenal Cascajares, y se incluyó una predicación del padre fray Salvador de Jenís, carmelita

70 Acta del pleno del Ayuntamiento de Valladolid dando cuenta de los actos, 3-5-1896, Archivo Municipal de Valladolid, caja 429.

71 ALONSO CORTÉS, 1943: 1036. Recordemos que por aquellos años se había comenzado a construir también el actual Panteón de Hombres Ilustres de Madrid, después de todo un siglo de proyectos. Véase al respecto: PASTOR MATEOS, 1970; BOYD, 12 (Madrid, 2004): 7-14; ÁLVAREZ BARRIENTOS, 18 (2005): 37-51. La creación de espacios para el recuerdo y homenaje de personajes ilustres alcanzó en España un carácter conflictivo en numerosas ocasiones porque la reivindicación nacional entraba en colisión con la local.

72 En el Panteón de Vallisoletanos Ilustres descansan también los restos de otros escritores como Emilio Ferrari, Rosa Chacel y Miguel Delibes.

73 El concurso se publicó en marzo de 1899 con un presupuesto de 23.366 pesetas (CANO DE GARDOQUI GARCÍA, 2000: 51-54).

74 WHALEY, 1981: 2. 
descalzo del convento de Valencia. A las 10 y media del mismo día se había celebrado una misa en la Iglesia de San Benito para solemnizar el acto, para la que se imprimieron invitaciones especiales ${ }^{75}$. Observamos, pues, la confusión de rituales que caracterizó a todo el siglo XIX. Si bien podría parecer lógico que tal combinación se produjera en el funeral, no resulta así en la erección de la estatua, al tratarse ese acto de un evento puramente civil.

La estatua de Carretero se situó en la entrada del Campo Grande, justo donde da comienzo el Paseo Zorrilla: en la Plaza de Zorrilla. Su ubicación en esta zona, en pleno ensanche de la ciudad, marcaba con claridad la importancia del personaje. Como ha señalado Carlos Reyero, este tipo de monumentos conmemorativos se situaban siempre o en los cascos históricos de las ciudades o en los ensanches burgueses ${ }^{76}$. La presencia urbanística del poeta tiene, pues, mucha más relevancia en su ciudad natal que en Madrid, ya que articula uno de los ejes principales de la ciudad. En Valladolid, la figura de Zorrilla lo llena todo, pues además de la vía urbana con su nombre (desde el 4 de febrero de 1893), desde 1884 existe en la ciudad el Teatro Zorrilla (que tiene en su sala de espera los retratos de los escritores vallisoletanos Gaspar Núñez de Arce, Emilio Ferrari, Leopoldo Cano y el propio Zorrilla). En octubre de 1907 se inauguró el Instituto José Zorrilla, que fue el primer instituto de enseñanza secundaria de la ciudad. En tiempos más modernos (1982), se abrió para los mundiales de fútbol el Nuevo Estadio José Zorrilla, que sustituyó al anterior estadio del mismo nombre, creado en 1942, y cuyo solar está ocupado en la actualidad por un centro comercial y unos jardines. La omnipresencia del poeta en la ciudad revela la completa identificación de la misma con el escritor y con el significado que la sociedad del momento le quiso atribuir.

Para finalizar este relato y sobre todo para oír la voz del protagonista pasivo de estos acontecimientos, conviene sacar a colación las últimas voluntades expresadas por el poeta en su testamento al hablar de su entierro, que poco tienen que ver con lo que se ha venido narrando:

... [1a] caja será envuelta y enterrada en el suelo y en tierra sin panteón, ni alegoría mundana que pretenda vida ni glorificación póstuma [...]. Sobre su sepultura no ha de ponerse más que una losa de piedra común, y por único recuerdo esta inscripción: 'El poeta José Zorrilla, hijo de Valladolid'. Alrededor de la fosa se pondrá una pequeña verja de hierro para evitar las profanaciones, y de esta fosa no permitirá jamás el Ayuntamiento que sus restos sean exhumados, so pretexto de trasladarlos a panteón nacional ni otro lugar alguno de mundana ostentación ${ }^{77}$.

75 Una esquela de este tipo puede encontrarse en el Archivo Municipal de Valladolid, caja 429.

76 REYERO, 1999: 375.

77 Testamento otorgado en Valladolid el 19 de enero de 1884, Archivo Histórico Provincial de Valladolid, protocolo $\mathrm{n}^{\circ}$ 18756, folio 92. ALONSO CORTÉS, 1943: 970. 


\section{CONCLUSIÓN}

Se ha señalado que en ceremonias como los funerales de estado existen tres formas complementarias de transmisión de valores que son la narrativa, la ritual y la icónica ${ }^{78}$. La primera haría referencia a la construcción discursiva que justifica que el personaje fallecido sea objeto de los homenajes; la segunda, a los procedimientos que marcan el protocolo del funeral de estado; y la tercera a los elementos visuales y a los lugares de la memoria que consagran el acontecimiento para el futuro de cara al asentamiento de la identidad colectiva. En el caso de José Zorrilla, la justificación discursiva viene dada por la interpretación que de su propia obra se realizó a lo largo del siglo, al ser considerado «el poeta de la tradición». Más conflictos genera la parte ritualística, ya que, como se ha podido observar, a la altura de finales del siglo todavía seguían estrechamente unidas las celebraciones religiosas y las cívicas, hasta el punto de que no se observan fronteras entre ellas. La disociación entre los protocolos religioso y civil habría de venir de sectores situados en los márgenes del sistema político. Por lo que respecta a la dimensión icónica, habría que señalar que el Estado, al menos en el caso de Zorrilla, no gestionó eficazmente las posibilidades que la obra del escritor ofrecía. Más éxito cabe reconocer al Ayuntamiento de Valladolid que contribuyó, como sucedió en el caso de otros ilustres fallecidos, a conformar una figura icónica mucho más sólida que el referente nacional y que es el ilustre local con proyección nacional. El uso ciudadano del personaje en su localidad de origen alcanzó (y alcanza hoy en día) un significado mucho más fuerte que el que tiene en el ámbito nacional, donde ha quedado únicamente como un episodio más del canon literario, pero sin presencia en la actual configuración del nacionalismo español.

\section{BibLiografía}

Alonso Cortés, Narciso, Zorrilla: su vida y sus obras, Valladolid, Librería Santarén, 1943. Álvarez Barrientos, Joaquín (ed.), Se hicieron literatos para ser políticos. Cultura y política en la España de Carlos IV y Fernando VII, Madrid, Biblioteca NuevaUniversidad de Cádiz, 2004.

Álvarez Barrientos, Joaquín, «Ramón de Mesonero Romanos y el Panteón de Hombres Ilustres», Anales de Literatura Española, 18 (Madrid, 2005), 37-51.

Álvarez Barrientos, Joaquín, Los hombres de letras en la España del siglo XVIII. Apóstoles y arribistas, Madrid, Editorial Castalia, 2006.

78 RADER, 2006: 24. 
Álvarez Barrientos, Joaquín, «Proyecto literario y oficio de escritor en Larra», en J. Álvarez Barrientos, J.M. Ferri Coll y E. Rubio Cremades (eds.), Larra en el mundo. La misión de un escritor moderno, Alicante, Publicaciones de la Universidad de Alicante, 2011; 17-40.

Ariès, Philippe, El hombre ante la muerte, Madrid, Taurus, 1983 (1977).

Ben-Amos, Avner, «Les funérailles de Victor Hugo», en Pierre Nora (dir.), Les Lieux de la mémoire, París, Gallimard, 1997, 1; 425-464.

Ben-Amos, Avner, Funerals, Politics and Memory in Modern France, 1789-1996, Oxford, Oxford University Press, 2000.

Bénichou, Paul, La coronación del escritor: ensayo sobre el advenimiento de un poder espiritual laico en Francia, México, F.C.E., 1981.

Bonnet, Jean-Claude, «Les morts illustres. Oraison fúnebre, éloge académique, nécrologie», en Pierre Nora (dir.), Les lieux de mémoire, París, Gallimard, 1997, II; 1831-1854.

Boyd, Carolyn, «Un lugar de memoria olvidado: el Panteón de Hombres Ilustres en Madrid», Historia y política: Ideas, procesos y movimientos sociales, 12 (Madrid, 2004), 7-14.

Cano de Gardoqui García, José Luis, Escultura pública en la ciudad de Valladolid, Valladolid, Ayuntamiento de Valladolid, 2000.

Cotarelo, Emilio, «Zorrilla académico», Boletín de la Real Academia Española, Madrid, Tipografía de la Revista de Archivos, Bibliotecas y Museos, año IV, tomo IV, febrero de 1917.

Cruz, Rafael, «El sabor fúnebre de la política española entre 1876 y 1940», en Rafael Cruz y Jesús Casquete (eds.), Políticas de la muerte. Usos y abusos del ritual fúnebre en la Europa del siglo XX, Madrid, La Catarata, 2009; 73-105.

Gérôme, Nicole, «La tradition politique des fêtes: interprétation et appropiation», en Alain Corbin, Nicole Gérôme y Daniel Tartakowsky (dirs.), Les usages politiques des fêtes aux XIX'-XX siècles, París, Publications de la Sorbonne, 1994.

González García-Valladolid, Casimiro, Valladolid, sus recuerdos y sus grandezas Valladolid, Juan Rodríguez Hernando, 1902, tomo III.

Guillén, Esperanza, Retratos del genio. El culto a la personalidad artística en el siglo XIX, Madrid, Cátedra, 2007.

Handelman, Donald, Models and mirrors: towards an anthropology of public events, Cambridge, Cambridge University Press, 1990.

Lissorgues, Yvan, «Clarín y Jovellanos», Cuadernos Dieciochescos, 11 (Salamanca, 2010), 141-152.

Mainer, José Carlos, «La invención de la literatura española», en Dolores Romero López (coord.), Naciones literarias, Madrid, Anthropos-UCM, 2006; 201-230.

Mesonero Romanos, Manuel, Los sepulcros de los hombres ilustres en los cementerios de Madrid, Madrid, Imprenta de Hernando y Cía, 1898.

Ordóñez Vergara, Javier, «La ciudad como escenario para la muerte en el siglo XIX: 
las honras fúnebres de M.A. Heredia», Baetica. Estudios de Arte, Geografía e Historia, 15 (Málaga, 1993), 21-29.

Palenque, Marta, «La coronación de Manuel José Quintana (1855)», Insula, 744 (Madrid, 2008), 26-29.

Pastor Mateos, Enrique, El Panteón de Hombres Ilustres, Madrid, Artes Gráficas Municipales, 1970.

Porpetta, Antonio, Escritores y artistas españoles. (Historia de una Asociación centenaria), Madrid, Asociación de Escritores y Artistas, 1986.

Rader, Olaf, Tumba y poder: el culto político a los muertos desde Alejandro Magno hasta Lenin, Madrid, Siruela, 2006.

Reyero, Carlos, La escultura conmemorativa en España. La edad de oro del monumento público, 1820-1914, Madrid, Cátedra, 1999.

Sánchez García, Raquel, «España y los españoles en la obra de José Zorrilla», Historia y Política: Ideas, procesos y movimientos sociales, 17 (Madrid, 2007), 205-222.

Sánchez García, Raquel, «Los funerales de Quintana», Cuadernos de Ilustración al Romanticismo, 17 (Cádiz, 2011a), 1-13.

Sánchez García, Raquel, «La coronación de José Zorrilla en 1889, negocio y espectáculo en la España de la Restauración», Mélanges de la Casa de Velázquez, 41, 2 (Madrid, 2011b): 185-203.

Ucelay da Cal, Enrique, «Enterrar al ciudadano o el tránsito que para el tránsito. El gran funeral público del prócer en la Barcelona ensanchada (1900-1939)», en Rafael Cruz y Jesús Casquete (eds.), Políticas de la muerte. Usos y abusos del ritual fúnebre en la Europa del siglo XX, Madrid, La Catarata, 2009; 129-169.

Urrea Fernández, Jesús, «El Museo de la casa natal del poeta José Zorrilla», Boletín. Real Academia de Bellas Artes de la Purísima Concepción, 43 (Valladolid, 2008), 57-64.

Varela, Javier, La muerte del rey: el ceremonial funerario de la monarquía española, 1500-1885, Madrid, Turner, 1990.

Vovelle, Michel, La mort et l'Occident. De 1300 à nos tours, París, Gallimard, 1983.

Whaley, Joachim (ed.), Mirrors of mortality. Studies in the Social History of Death, Londres, Europa Publications Limited, 1981.

Recibido: $21 / 09 / 2012$

Aceptado: 30/04/2013 